\title{
A CASE OF "RAYISM"- TROPICAL STINGRAY INTOXICATION WITH A FAVORABLE OUTCOME
}

\author{
Yanko T. Iliev, \\ Vladimir V. Bozhilov ${ }^{2}$ \\ ${ }^{1}$ Medical University, Plovdiv \\ ${ }^{2}$ St. George University Hospital, \\ Plovdiv
}

\begin{abstract}
Summary
Tropical fresh water stingrays have become quite popular among amateur and professional aquarists due to their attractive appearance. However, the species may have a high life-threatening potential. Stingray intoxication is rare in Eastern Europe and there is no specific antivenin available. We present the first case of "rayism" envenomation caused by sp. Reticulatus in Eastern Europe. The patient was a 63 -year-old amateur aquarist, with a history of ischaemic heart disease and allergy to NSAIDs. He got stung while cleaning a stingray fish tank and was admitted to the department of clinical toxicology $40 \mathrm{~min}$ following the incident, with symptoms of moderate intoxication: accentuated local toxic syndrome - mild bleeding at the sting site, worsening and excruciating (89/10) pain in his left hand and forearm, feeling of "burning" in the arm, accompanying toxic symptoms vertigo, malaise, fatigue, sweating and tightness in the chest. No antitoxin was available and the treatment plan included local aseptic treatment of the wound, antitetanus prophylaxis, fluoroquinolone-type antibiotic prophylaxis, antihistamine, a corticosteroid and i.v. infusions. Thermal therapy (immersing the arm in hot, $45^{\circ} \mathrm{C}$ tap water) completely reduced the pain within 5 hours. Full recovery was achieved on the $3^{\text {rd }}$ day after the exposure. A toxicologist should react adequately in the setting of a rare intoxication even when a specific antidote is not available. Thermal therapy proved to be effective in the case of stingray envenomation.
\end{abstract}

Key words: intoxication, tropical stingray, thermal therapy

\section{Introduction}

The popularity of keeping exotic animal species as pets has been steadily rising in the recent years. Tropical fresh water stingrays have become quite popular for amateur and professional aquarists due to their attractive appearance. Stingrays in the Northern Hemisphere belong to the Dasyaditae family [1]. The effects of their stinging are called "rayism" and they have a high life-threatening potential $[2,3]$. The toxic envenomation is a rare event in Eastern Europe. 


\section{Case presentation}

We present a 63-year-old male, admitted as an emergency to the Department of Clinical Toxicology at St. George University Hospital Plovdiv (case history 52460/559, 12.09.2013). On admission he was diagnosed with toxic effects due to tropical stingray (s. Reticulatus) envenomation. Previous medical history included ischaemic heart disease and allergy to NSAIDs. The patient was stung on the left middle finger by a domestic tropical stingray $\mathrm{sp}$. Reticulatus while cleaning a fish tank. He applied a compressive dressing to the hand aiming to manage moderate bleeding that had been going for nearly 30 minutes and an increasing, almost excruciating (8-9/10) burning pain in his left hand and forearm. In the meantime he started feeling dizzy, fatigued, sick, and generally ill. He had a headache, sweating and chest tightness. On admission, his left arm was swollen, with regional lymphangitis and lymphadenitis to the level of left brachium. There was a moderate bleeding from the $2-\mathrm{cm}$ wound. There were no residual fragments of the barb in the wound. All data suggested a moderate grade of intoxication.

On the initial clinical examination the patient was fully conscious, adequate and orientated, and apyrexial. Head and neck were normal and the thyroid gland did not feel enlarged on palpation. Skin and mucous membranes looked pink. Lungs were bilaterally clear with good air entry. Heart sounds were also clear, without bruit and no signs of arrhythmia. The blood pressure was $165 / 100 \mathrm{~mm} \mathrm{Hg}$, heart rate was 70 b.p.m. The abdomen was soft, non-tender, with normal bowel sounds. There was a linear cut wound, approximately $2 \mathrm{~cm}$ long in the area of left middle finger, the bleeding of the wound seemed moderate to minimal. The left arm was edematous with regional lymphangitis and lymphadenitis up to the level of brachium. There were no signs of neurological deficit. Finding from the laboratory tests, arterial blood gas analysis and the ECG record were normal.

As there was no specific antidote available, the treatment applied was as follows: the wound site was cleaned aseptically, and the patient was given Tetatox" (adsorbed tetanus vaccine) $0.5 \mathrm{ml}$ i.m., prophylactic treatment with antibiotic (Ciprofloxacin 500mg, bd), antihistamine (Loratidine $10 \mathrm{mg} \mathrm{bd}$ ) and a corticosteroid (methylprednisolone $80 \mathrm{mg}$ stat, with following dose tapering). To achieve depuration and detoxication of the toxin, i.v. fluids were introduced (Ringer, Dextrose/NS, and Dextrose $5 \%)$. The left arm was lifted above the level of the heart and immersed for $90 \mathrm{~min}$ in hot water $\left(45^{\circ}\right.$ C), which was well tolerated by the patient although even higher temperatures have been recommended [4].

ECG, oxygen saturation, heart rate and blood pressure were continuously monitored throughout the hospital stay and remained stable. No NSAIDs were given though recommended by some researchers [5] because of the previous medical history of allergic reaction to NSAIDs.

Significant reduction of the local and general toxic symptoms was achieved within 5 hours of the initiating the treatment. No complications occurred for 48 hours after the exposure. The attempted thermal therapy led to almost complete reduction of the pain in the affected extremity.

\section{Discussion}

Tropical stingray Reticulatus do not use the poisonous sting to catch pray, but rather for selfdefense when intimidated [6]. The barb has a connecting tissue lining where the poisonous glands open [7]. That trauma caused by the sting itself can be life-threatening if major blood vessels are lacerated [6] or even fatal [8] if the poison is injected directly in the thoracic cavity and pericardium $[6,9]$. The poison is a watersoluble, term labile protein-based toxin, consisting of serotonin, 5-nucleotidaze and phosphodiesterase. The excruciating pain at the site of the impact is caused by both the serotonininduced smooth muscle contractions and by the soft tissue destruction and necrosis potentiated by the 5 -nucleotidaze and the phosphodiesterase. [7]. As the toxin is a term labile protein at temperatures of $37-56^{\circ} \mathrm{C}$, its compounds denature and are deactivated even if already absorbed in the tissues. These tissue effects can last up to 48 hours [7]. The onset of the symptoms is always acute, within 30 minutes of exposure with rapid development of local edema, erythema, cyanosis and local lymph node involvement, as was observed in this case. The general toxic symptoms include fatigue, dizziness, sweating, nausea and vomiting, headache, convulsions, paralysis, hypotension, respiratory distress, conductive impairment of hearth rhythm (complete AV block), and syncope. The most severe cases can present with 
respiratory arrest and shock. If no adequate and timely antimicrobial prophylaxis is started there is a high risk of late wound infections [6,7].

Patients with allergic history can also suffer with skin and mucous pathological reactions, angioedema, bronchial spasm and anaphylaxis.

Fresh water stingray envenomation is very rare in Bulgaria and as such it can make the adequate and timely treatment treacherous. Of outmost importance in the case reported were specifying the stingray taxonomy by the patient, the medical treatment within 40mins after the accident, the site of the sting, the small amount of toxin injected or the type of the sting itself (protective and/or warning!) and the effectiveness of the hot water therapy [4, 11-13].

Cryotherapy, though often suitable in other cases of animal envenomation, was definitely contraindicated in that situation $[6,12]$. The method of hot water immersion was applied up to the 5th hour of admission, much longer than what other researchers have reported, i.e. 30 minutes [4].

Treatment with fluoroquinolone to prevent wound infection proved reasonable from a clinical of view: no infection occurred. This result correlates with the high frequency of fluorquinolone-sensitive microorganisms engaged in similar accidents reported by other researchers [7, 10, 14]. Routine storage and usage of specific stingray antisera in Bulgaria is practically not applicable at the moment. There is no specific antiserum for Reticulatus poisonings [7] and the other sera for the Dasyatidae family would not be effective. The situation in other European countries is the same, for instance in France [15].

\section{Conclusion}

We conclude that a toxicologist should react adequately in the setting of a rare intoxication even when a specific antidote is not available. Thermal therapy in sp. Reticulatus envenomation proves to be an effective therapeutic modality.

\section{References}

1. Cermeño JR, Cermeño JJ, Salazar N, Gómez de Salazar N. 2005. [Rayismo: Aspectos epidemiológicos y clínicos. Estado Bolívar,Venezuela]. Revista Kasmera. 2005;33(1):46-50. Spanish.
2. Pastrana J, Blasco R, Erce R, Pinillos MA. [Animal sting and bites]. An Sist Sanit Navar. 2003;26 (Suppl 1):225-41. Spanish.

3. Steve Grenard. Stingray injuries, envenomation and medical management. [cited 2014 Jan 14]. Available from

http://www.potamotrygon.de/fremdes/stingray $\% 2$ 0article.htm

4. Loten C, Scokes B, Worsley D, Seymour JE, Jiang $\mathrm{S}$, Isbister GK. A randomised controlled trial of hot water $\left(45^{\circ} \mathrm{C}\right)$ immersion versus ice packs for pain relief in blue bottle stings. Med J Aust. 2006;184(7):329-33.

5. Clark RF, Girard RH, Rao D, Ly BT, Davis DP. Stingray envenomation: a retrospective review of clinical presentation and treatment in 119 cases. J Emerg Med. 2007;33(1):33-7.

6. Rodriguez HGR, Sanchez EC, Mendez JD. Stingray poisoning, a careless aspect in Mexico. Advances in Enviromental Biology. 2008;2(2):5462.

7. Meyer PK. Stingray injuries. Wilderness Environ Med. 1997;8(1):24-8.

8. Fenner PJ, Williamson JA, Skinner RA. Fatal and non-fatal stingray envenomation. Med J Aust. 1989;151(11-12):621-5.

9. Cazorla D, Loyo J, Lugo L, Acosta M. [Clinical, epidemiological and treatment aspects of 10 cases of saltwater stingray envenomation]. Rev Invest Clin. 2009;61(1):11-7. Spanish.

10. Perkins RA, Morgan SS. Poisoning, envenomation, and trauma from marine creatures. Am Fam Physician. 2004;69(4):885-90.

11. Atkinson PRT, Boyle A, Hartin D, McAuley D. Is hot water immersion an effective treatment for marine envenomation? Emerg Med J. 2006;23(7):503-8.

12. Smarrito S, Smarrito F, Leclair O, Labbe JL. [ Surgical management of stingray injuries. About two clinical cases]. Ann Chir Plast Esthet. 2004;49(4):383-6. French.

13. Tse AE, Evans DP, Counselman FL. A pain in the wrist: stingray envenomation. West J Emerg Med. 2012;13(1):80-1. doi:10.5811/westjem.2011. 8.6878 .

14. Brown TP. Diagnosis and management of injuries from dangerous marine life. MedGenMed. 200;7(3):5.

15. de Haro L, Pommier P. Envenomation: a real risk of keeping exotic house pets. Vet Hum Toxicol. 2003;45(4):214-6. 